\title{
Produção de antígeno nucleoprotéico do vírus da artrite-encefalite caprina e comparação com o do vírus Maedi-Visna para utilização em teste de imunodifusão em ágar gel ${ }^{1}$
}

\author{
Silvio R. O. Abreu ${ }^{2}$, Roberto S. Castro ${ }^{2}$, Sérgio A. Nascimento ${ }^{2}$ e Marleide G. Souza ${ }^{2}$ \\ ABSTRACT.- Abreu S.R.O., Castro R.S., Nascimento S.A. \& Souza M.G. 1998. [CAEV nucleoproteic \\ antigen production and comparison with Maedi-Visna antigen in the immunodiffusion \\ test.] Produção de antígeno nucleoprotéico do vírus da artrite-encefalite caprina e comparação \\ com o do vírus Maedi-Visna para utilização em teste de imunodifusão em ágar gel. Pesquisa Veterinária \\ Brasileira 18(2):57-60. Depto Med. Veterinária, Universidade Federal Rural de Pernambuco, Rua D. \\ Manoel de Medeiros s/n, Dois Irmãos, Recife, PE 52171-030, Brazil. \\ A comparison of Maedi-Visna virus (MVV) and Caprine Arthritis-encephalitis virus (CAEV) \\ antigens for detection of antibodies to CAEV was performed using sera from 120 goats. The \\ sensitivity and specificity of the immunodiffusion test using MVV antigen compared to that of \\ CAEV antigen was $77.3 \%$ and $100 \%$, respectively $\left(X^{2}, p<0.01\right)$. These results suggested that \\ only CAEV antigen should be used in immunodiffusion tests for CAEV diagnosis.
}

INDEX TERMS: Caprine arthritis-encephalitis, Maedi/Visna, antigen, immunodiffusion.

\begin{abstract}
RESUMO.- Foi feita uma comparação entre os antígenos (Ag), preparados a partir dos vírus Maedi-Visna (MVV) e Artriteencefalite Caprina (CAEV) para deteç̧ão de anticorpos contra o CAEV em 120 amostras de soro caprino. A sensibilidade $e$ especificidade relativa da imunodifusão em ágar gel (IDAG) usando-se Ag MVV em relação ao Ag CAEV, foi 77,3\% e 100\%, respectivamente $\left(X^{2}, p<0,01\right)$. Assim, para diagnóstico de infecção pelo CAEV recomenda-se apenas o uso de Ag preparado a partir do CAEV.
\end{abstract}

TERMOS DE INDEXAÇÃO: Artrite-encefalite caprina, maedi/visna, antígeno, imunodifusão.

\section{INTRODUÇ̃̃O}

A Artrite-Encefalite Caprina (CAE) é uma enfermidade de caprinos causada por um lentivírus (CAEV), antigenicamente reacionado com o vírus Maedi-Visna (MVV) ou Pneumonia Progressiva dos ovinos (OPP) (Gogolewski et al. 1985), que se encontra disseminada principalmente nos países onde a caprinocultura leiteira é fortemente tecnificada (Adams et al. 1984, Peretz et al. 1993). A infecção pelo CAEV é caracterizada por alta prevalência de soropositividade e, geralmente,

\footnotetext{
${ }^{1}$ Aceito para publicação em 9 de fevereiro de 1998.

${ }^{2}$ Depto Med. Veterinária, Universidade Federal Rural de Pernambuco (UFRPE) Rua D. Manoel de Medeiros s/n, Dois Irmãos, Recife, PE 52171-030, Brasil. E-mail:rscastro@nelore.npde.ufrpe.br
}

baixa morbidadade. Os animais infectados, mesmo aparentemente saudáveis ou soronegativos, podem disseminar o vírus continuamente (Rimstad et al. 1993).

Por essas características da doença e por não existirem sinais clínicos patognomônicos torna-se necessário o auxílio de testes laboratoriais que permitam seu diagnóstico. $\mathrm{O}$ teste laboratorial para diagnóstico de infecção pelo CAEV mais difundido é o de imunodifusão em ágar gel (IDAG), que tem grande aceitação na execução de testes de rotina em rebanhos, devido ao custo relativamente baixo, à boa sensibilidade e especificidade, além da praticidade de execução e leitura (Harkiss \& Watt, 1990).

No Brasil os testes sorológicos (utilizando-se Ag MVV ou do vírus OPP, importados) têm revelado a ocorrência dessa enfermidade nos Estados do Rio Grande do Sul (Moojen et al. 1986), Bahia (Fiterman 1988, Assis \& Gouveia 1994), Ceará (Pinheiro et al. 1989, Assis \& Gouveia 1994), Pernambuco (Castro et al. 1994, Saraiva Neto et al. 1995) e Rio de Janeiro (Cunha \& Nascimento 1995).

A escolha do tipo de $\mathrm{Ag}$ para pesquisa de anticorpos para CAEV tem sido motivo de controvérsia, pois, embora haja recomendação do emprego do $\mathrm{MVV}$, recentemente tem sido demonstrado que a IDAG com glicoproteínas do CAEV é mais sensível que a com Ag do vírus OPP (Knowles et al. 1994). É sabido que a região mais conservada do genoma do CAEV, e que mostra maior homologia com lentivírus ovino, é a codificada pelo gene gag, que é expresso na forma de 
nucleoproteína (Pyper et al. 1986, Saltarelli et al. 1990), e que pode ocorrer resposta imunológica seletiva para glicoproteínas ou nucleoproteínas do CAEV, dependendo da fase de infecção (Johnson et al. 1983, Rimstad et al. 1994). Este trabalho foi elaborado com o objetivo de comparar antígenos nucleoproteicos do MVV e do CAEV para pesquisa de anticorpos para CAEV em soros caprinos.

\section{MATERIAL E MÉTODOS}

As células de membrana sinovial caprina (MSC), utilizadas para replicação viral, foram obtidas a partir de cabrito soronegativo, oriundo de cabra também soronegativa para o CAEV pelo teste de IDAG. As culturas foram estabelecidas a partir de explantes. Após remoção dos tecidos peri-articulares, as cavidades articulares foram abertas, as membranas sinoviais delicadamente dissecadas, umedecidas com meio essencial mínimo (MEM-Eagle, contendo penicilina, estreptomicina e anfotericina B), seccionadas em fragmentos de aproximadamente $1,0 \mathrm{~mm}$, que foram cuidadosamente distribuídos na superfície de cultivo de garrafas de $25 \mathrm{~cm}^{2}$, incubadas a $37^{\circ} \mathrm{C}$ em atmosfera de $5 \%$ de $\mathrm{CO}_{2}$. Depois de, aproximadamente, 30 minutos foram colocados 2,0 ml de MEM suplementado com $15 \%$ de soro fetal bovino (SFB), suficientes para cobrir os explantes. Passados quatro dias em estufa de $\mathrm{CO}_{2}$ a $37^{\circ} \mathrm{C}$, foram acrescidos mais 3,0 ml de MEM com $15 \%$ de SFB. No décimo segundo dia de cultivo os explantes foram removidos, as monocamadas tripsinizadas e subcultivadas na proporção de 1:1, para a obtenção de monocamadas. Finalmente, as células foram mantidas por passagens seriadas, na proporção de 1:3, bem como por criopreservação em $\mathrm{N}_{2}$ líquido.

Para a produção do Ag foi utilizada a amostra de $\mathrm{CAEV}^{3}$ isolada nos Estados Unidos da América (Crawford et al. 1980) replicada em células de MSC. Para isto, $1 \mathrm{ml}$ de suspensão viral estocada em $\mathrm{N}_{2}$ líquido foi diluída 1:10 e inoculada $\left(2 \mathrm{ml}\right.$ por garrafa de $75 \mathrm{~cm}^{2}$ de área de cultivo) em monocamadas subconfluentes. Após 2 horas a $37^{\circ} \mathrm{Co}$ inóculo foi removido e substituido por $15 \mathrm{ml}$ de MEM contendo $2 \%$ de SFB. O sobrenadante foi colhido semanalmente e estocado $20^{\circ} \mathrm{C}$.

$\mathrm{O} \mathrm{Ag}$ foi preparado pela concentração por diálise (modificada de Cutlip et al. 1977), após descongelamento e centrifugação dos sobrenadantes a 3000 r.p.m. durante 20 minutos. O clarificado foi removido e dialisado (tubo de diálise de $33 \times 21 \mathrm{~mm}$; INLAB) contra PEG 8000 a $10 \%$ em salina fosfatada, até a concentração de cerca de 50 vezes, quando foi colhido e estocado a $-20^{\circ} \mathrm{C}$. Após descongelamento, o concentrado foi submetido a tratamento com éter etílico, em partes iguais, e homogeneizado durante 10 minutos, para liberação das proteínas internas do virion. Em seguida, este material foi centrifugado a 2000 r.p.m. por 10 minutos para a separação e remoção do éter.

O Ag de MVV utlizado na comparação com o CAEV foi o produzido pelo Institut Pourquier (Montpellier, França) constituído da nucleoproteina p26 do vírus MVV, conforme indicado pelo fabricante.

As amostras de soro foram obtidas no banco de soro caprino do Laboratório de Doenças Infecto-Contagiosas do Departamento de Medicina Veterinária da UFRPE, onde estavam estocadas a $-20^{\circ} \mathrm{C}$, colhidas de animais das raças Saanen, Toggenburg e Parda Alemã, de rebanhos leiteiros, no total de 100 amostras; assim como de

\footnotetext{
${ }^{3}$ Gentilmente cedida por Dr. Yahia Chebloune (Laboratoire Associé de Recherches Sur Les Lentivirus Chez Les Petits Ruminants, INRA - ENVL, França).
}

animais sem raça definida oriundos do Sertão de Pernambuco e da Paraíba, no total de 20 amostras.

Para realização do teste foi preparado ágar noble (Difco) a $1,2 \%$ em tampão borato ( $2 \mathrm{~g}$ de $\mathrm{NaOH}, 9 \mathrm{~g}$ de $\mathrm{H}_{3} \mathrm{BO}_{3}$, 11 de $\mathrm{H}_{2} \mathrm{O}$ destilada deionizada. A solução foi aliquotada e mantida a $4-8^{\circ} \mathrm{C}$. No momento do uso o ágar foi liquefeito e distribuído em placas de Petri de plástico descartáveis de $90 \mathrm{~mm}$ de diâmetro (16 $\mathrm{ml}$ por placa), permanecendo à temperatura ambiente até sua solidificação $\mathrm{e}$, posteriormente, mantidas a $4-8^{\circ} \mathrm{C}$. No dia seguinte, o gel foi perfurado com um molde, de maneira a formar sete poços de $8 \mathrm{~mm}$ de diâmetro e $3 \mathrm{~mm}$ de distância entre as bordas, sendo um central e os outros seis distribuídos em torno deste, de acordo com o preconizado pelo fabricante (Institut Pourquier, Montpellier, França), para teste de IDAG para MVV.

No momento da execução dos testes, o soro padrão e os testes foram distribuídos em poços alternados e o antígeno no poço central. $\mathrm{O}$ soro padrão utilizado para o Ag CAEV foi um soro caprino forte positivo pelo teste de IDAG do kit comercial, que detecta anticorpos contra a nucleoproteína p26 do vírus MVV (Institut Pourquier, Montpellier, França).

As leituras foram realizadas após 24,48 e 72 horas, observandose a formação de linha de precipitação entre o soro teste e o $\mathrm{Ag}$, sendo considerado positivo o soro cuja linha de precipitação apresentou identidade com a linha formada pelo soro padrão, e negativos aquele onde não houve formação de linha de precipitação ou a linha formada não teve identidade com a do soro padrão (linha inespecífica). Para efeito de cálculo os soros inconclusivos foram considerados negativos. Os soros positivos foram classificados em fraco positivo $(+)$, positivo $(++)$ e forte positivo $(+++)$, de acordo com a intensidade e a posição da linha formada entre o soro e o $\mathrm{Ag}$ (quanto mais intensa e mais próxima do poço do $\mathrm{Ag}$ a linha se formava, mais forte era considerada a reação).

Os resultados dos 120 soros testados pelos dois $\mathrm{Ag}$ foram distribuídos em uma tabela de contingência $2 \times 2$ e utilizados como referência para o cálculo da sensibilidade e da especificidade relativas (Thiry \& Pastoret 1992). Os resultados dos testes foram submetidas à análise estatística pelo teste de qui-quadrado $\left(\mathrm{c}^{2}\right)(\mathrm{p}<0,01)$ (Dean et al. 1990).

\section{RESULTADOS}

Na obtenção de células de MSC utilizando-se a região metacarpiana de ambos os membros houve produção de duas a três garrafas de cultura celular de $25 \mathrm{~cm}^{2}$ de área de cultivo que se apresentaram viáveis para a primeira sub-cultura em cerca de 10 a 12 dias. As células sub-cultivadas com intervalos de 3 a 7 dias mantiveram-se em níveis satisfatórios de vitalidade e produtividade por mais de 20 sub-cultivos. O CAEV replicou-se bem tanto em células de baixa $\left(5^{\mathrm{a}}\right.$ a $\left.7^{\mathrm{a}}\right)$ como em alta $\left(17^{\mathrm{a}}\right.$ a $\left.18^{\mathrm{a}}\right)$ passagens, produzindo efeito citopático caracterizado por vacuolização e formação de sincícios.

A partir de $1 \mathrm{ml}$ de sobrenadante de cultura de MS infectada, obteve-se vírus suficiente para inocular 5 garrafas de MSC de $75 \mathrm{~cm}^{2}$ de superfície de cultivo, que forneceram em 4 coletas, aproximadamente, $300 \mathrm{ml}$ de sobrenadante rico em partículas virais que concentrados renderam cerca de $6 \mathrm{ml}$ de Ag, suficientes para testar 180 soros.

Dos 120 soros testados, o Ag CAEV produzido classificou 75 como positivos e 45 como negativos. Esses soros, quando testados frente ao $\mathrm{Ag}$ MVV resultaram em 58 positivos e 17 negativos (Sensibilidade relativa de $77,3 \%$ ). Os 45 soros clas- 
Quadro 1. Resultados dos testes de IDAG utilizando-se os Ag CAEV e MVV

\begin{tabular}{|c|c|c|c|}
\hline \multirow[t]{2}{*}{$\begin{array}{l}\text { Resultado do teste } \\
\text { com o Ag MVV }\end{array}$} & \multicolumn{2}{|c|}{$\begin{array}{c}\text { Resultado do teste } \\
\text { com o CAEV }\end{array}$} & \multirow[t]{2}{*}{ Total } \\
\hline & Positivo & Negativo & \\
\hline Positivo & 58 & 0 & 58 \\
\hline Negativo & 17 & 45 & 62 \\
\hline Total & 75 & 45 & 120 \\
\hline
\end{tabular}

sificados como negativos pelo Ag CAEV apresentaram o mesmo resultado frente ao $\mathrm{Ag} \mathrm{MVV}$ (Especificidade relativa de 100\%). Apesar da concordância de $86 \%$ entre os testes, houve diferença estatisticamente significativa entre os resultados obtidos com os antígenos CAE e MVV ( $\mathrm{p}<0,01)$ (Quadro 1).

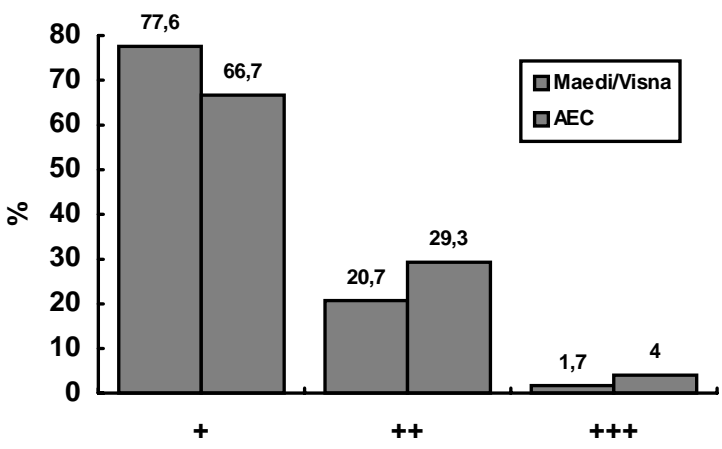

Fig. 1. Distribuição de frequência dos soros positivos em função da intensidade de formação da linha de precipitação frente aos $\mathrm{Ag}$ CAEV e MVV.

Para melhor avaliação dos resultados foi comparada a distribuição de intensidade na formação das linhas de precipitação entre os soros testes e cada $\mathrm{Ag}$, onde observa-se um maior número de soros positivos $(++\mathrm{e}+++)$ para o teste com o Ag CAEV (Fig. 1).

\section{DISCUSSÃO}

A cultura de células de MSC demonstrou ser relativamente simples quanto à sua técnica de obtenção, desde que se permitisse que os explantes aderíssem à garrafa durante cerca de 30 minutos. Tempo inferior provocava o deslocamento celular quando da colocação do meio de cultura, e tempo superior ressecava a base do explante de forma a não permitir a formação da camada de células.

De acordo com os dados apresentados no Quadro 1, observou-se igual especificidade, porém menor sensibilidade relativa do Ag MVV frente ao Ag CAEV. Os resultados discordantes podem ser explicados pela diferença antigênica entre os dois vírus, apesar da menor divergência no gene gag, que codifica as nucleoproteínas (Pyper et al. 1986, Saltarelli et al. 1990), principais componentes dos Ag avaliados (Adams \&
Gorhan 1986). Por outro lado, Castro et al. (dados não publicados) têm observado que soros negativos pelo teste de IDAG com Ag MVV deram reação positiva frente a esse teste utilizando Ag glicoproteico produzido com o CAEV, assim como quando testados por ELISA indireto com Ag CAEV.

Adicionalmente, ficou demonstrado (Fig. 1) que o Ag CAEV apresentou maior número de reações mais intensas $(++\mathrm{e}$ $+++)$. Ressalte-se que muitos soros com reação menos intensa $(+)$ frente ao Ag MVV, apresentaram reações mais fortes frente ao CAEV. É importante salientar, apesar de não estar exposto no trabalho, que o estado de positividade e negatividade de cada soro era previamente conhecido (com exceção dos 20 soros do Sertão), pois haviam sido submetidos, há cerca de dois anos e meio, a IDAG (Ag nucleoprotéico do MVV), e congelados a $-20^{\circ} \mathrm{C}$. Alguns soros anteriormente fraco positivos com o $\mathrm{Ag} \mathrm{MVV}$, passaram a não mais reagir com esse Ag, porém revelaram-se positivos ao Ag CAEV, diminuindo a sensibilidade relativa do Ag MVV. Nesse período pode ter ocorrido diminuição no título de Ac dos soros, o que sugere maior capacidade de detecção, por parte do Ag CAEV, de soros com baixos títulos.

No que se refere às leituras, apesar de muitos soros em ambos os testes já haverem formado linha de precipitação com $24 \mathrm{~h}$, somente a partir de $72 \mathrm{~h}$ os resultados tornaram-se estáveis, denotrando a importância do fator tempo na leitura e registro dos resultados.

Finalmente, conclui-se que o Ag nucleoprotéico, preparado a partir da técnica de concentração por diálise e tratamento com éter etílico, do CAEV mostrou-se mais eficiente do que o Ag MVV na deteç̧ão de Ac contra o CAEV através da IDAG. Considerando-se a superioridade do uso de glicoproteínas do CAEV quando comparadas com MVV (Knowles et al. 1994), a produção seletiva de resposta imunológica para glico ou nucleoproteínas do CAEV (Johnson et al. 1983, Rimstad et al. 1994) e a consequente necessidade do uso dessas duas principais proteínas virais na detecção do maior número de animais soropositivos para CAEV (Adams \& Gorhan 1986), recomenda-se a produção Ag glicoprotéicos e nucleoprotéicos a partir do CAEV (preferencialmente de amostras isoladas no Brasil), ao invés do MVV, e sua utilização para testes de monitoramento, visando o controle ou erradicação da AEC em nossos rebanhos, assim como nos estudos epidemiológicos.

\section{REFERÊNCIAS}

Adams D.S. \& Gorham J.R. 1986. The gp135 of caprine arthritis-encephalitis affords greater sensitivity than the p28 in immunodiffusion serology. Res.Vet. Sci. 40:157-160.

Adams D.S., Oliver R.E., Ameghino E., DeMartine J.C., Verwoerd D.W., Howers D.J., Waghela S., Gorham J.R., Hyllseth B., Dawson M., Trigo F.J. \& McGuire, T.C. 1984. Global survey of serological evidence of caprine arthritisencephalitis virus infection. Vet. Rec. 115(19):493-495.

Assis A.P.M.V. \& Gouveia A.M.G. 1994. Evidência sorológica de Lentivirus (Maedi Visna/Atrite-encefalite caprina) em rebanhos nos Estados de MG, RJ, BA e CE. Anais $23^{\circ}$ Congr. Bras. Med. Vet., Olinda, Pernambuco, p. 104. (Resumo)

Castro R.S., Alves S. \& Abreu S.R.O. 1994. Evidência sorológica de infecção pelo vírus da artrite-encefalite caprina em caprinos leiteiros de Pernambuco. Arq. Bras. Med. Vet. Zoot. 46(5):571-572. 
Crawford T.B., Adams D.S., Cheevers W.P. \& Cork L.C. 1980. Chronic arthritis in goats caused by a retrovirus. Science 207 (4434):997-999.

Cunha R.G. \& Nascimento M.D. 1995. Ocorrência de anticorpos para o vírus da artrite-encefalite caprina em soros de caprinos do Estado do Rio de Janeiro. Revta Bras. Med. Vet. 17(2):72-75.

Cutlip R.C., Jackson T.A. \& Laird G.A. 1977. Immunodiffusion test for ovine progressive pneumonia. Am. J. Vet. Res. 38(7):1081-1084.

Dean A.G., Dean J.A. \& Burton A.H. 1990. Epi Info, Version 5: A Word processing, data base, and statistic program for epidemiology on microcomputers. Center for Disease Control, Atlanta, Georgia.

Fiterman I.R. 1988 Constatação do complexo artrite-encefalite caprina em um plantel de caprinos no Estado da Bahia. Anais $21^{\circ}$ Congr. Bras. Med. Vet. Salvador, Bahia, p. 33. (Resumo)

Gogolewski R.P., Adams D.S., McGuire T.C., Banks K.L. \& Cheevers W.P. 1985 Antigenic cross reactivity between caprine-arthritis encephalitis, visna and progressive pneumonia viruses involves all virion-associated proteins and glycoproteins. J. General Virology 66:1233-1240.

Harkiss G.D. \& Watt N.J. 1990. Lentivirus infections and their detection. Goat Vet. Soc. J. 11(1):19-25.

Johnson C.G., Barbet A.F., Klevjer-Anderson P. \& McGuire T.C. 1983. Preferential immune response to virion surface glicoproteins by caprine arthritisencephalitis virus-infected goats. Infect.Immun. 41(2):657-665.

Knowles D.P., Evermann J.F., Shropshire C., VanderShchalie J., Bradway D. Gezon H.M. \& Cheevers W.P. 1994. Evaluation of agar gel immunodifusion serology using caprine and ovine lentiviral antigens for detection of antibody to caprine arthrite-encefalitis virus. J. Clin. Microbiol. 32(1):243245 .
Moojen V., Soares H.C., Ravazzolo A.P., Pizzol M. \& Gomes M. 1986. Evidência de infecção pelo lentivírus (maedi/visna-artrite-encefalite caprina) em caprinos no Rio Grande do Sul, Brasil. Arq. Fac. Vet. Univ. Fed. Rio Grande do Sul 1(14):77-78.

Peretz G., Asso J. \& Devillechaise P. 1993. Le C.A.E.V: Revue des connaissances actuelles et conséquences pratiques. Rev. Méd. Vét. 144(2):93-98.

Pinheiro R.R., Egito A.S., Santa Rosa J. \& Pinheiro A.A. 1988. Artrite-Encefalite Caprina Viral (CAEV). Comunicado técnico 19, Embrapa-CNPC, Sobral, Ceará. $5 p$.

Pyper J.M., Clements J.E., Gonda M.A. \& Narayan, O. 1986. Sequence homology between cloned caprine arthritis encephalitis virus and visna virus, two neurotropic lentiviruses. J.Virology 58(2):665-670.

Rimstad E., East N. E., Torten M., Higgins J., DeRock E. \& Pedersen N. C. 1993. Delayed seroconversion following naturally acquired caprine arthritis-encephalitis virus infection in goats. Am. J. Vet. Res. 54(11):1858-1862.

Rimstad E., East N., DeRock E., Higgins J. \& Pedersen N.C. 1994. Detection of antibodies to caprine arthritis-encephalitis virus using recombinant gag proteins. Arch. Virology 134(3-4):345-356.

Saltarelli M., Querat G., Konings D.A.M., Vigne, R. \& Clements J. 1990. Nucleotide sequence and transcriptional analysis of molecular clones of CAEV which generate infectious virus. Virology 179(1):374-364.

Saraiva Neto A.O, Castro R.S, Birgel E.H. \& Nascimento S.A. 1995. Estudo soro-epidemiológico da artrite-encefalite caprina em Pernambuco. Pesq. Vet. Bras. 15(4):121-124.

Thiry E. \& Pastoret P.P. 1992. L'évaluation des méthodes diagnostiques. Annales Méd. Vét. 136:269-272. 